\title{
PENGARUH KONSTRUKSI SUMUR GALI TERHADAP KUALITAS BAKTERIOLOGIS AIR BERSIH DI PUSKESMAS TEKUNG KABUPATEN LUMAJANG TAHUN 2017
}

\author{
Cardina Apriliana, Darjati, Bambang Sunarko
}

\begin{abstract}
ABSTRAK
Penduduk di wilayah kerja Puskesmas Tekung sarana air bersih yang digunakan adalah sumur gali. Sumur gali berjumlah 7.320 , namun yang memenuhi syarat kesehatan yaitu 103. Konstruksi sumur yang tidak memenuhi syarat kesehatan dapat menyebabkan pencemaran pada air bersih. Tujuan penelitian ini adalah untuk mengetahui pengaruh konstruksi sumur gali terhadap kualitas bakteriologis air bersih.

Penelitian ini merupakan penelitian survei analitik dengan menggunakan pendekatan cross sectional. Variabel pada penelitian ini yaitu kualitas bakteriologis air bersih, lokasi, dinding sumur, bibir sumur dan lantai. Populasi pada penelitian ini yaitu sebanyak 995. Teknik pengambilan sampel menggunakan proporsional random sampling. Jumlah sampel yang diambil sebanyak 91. Analisa data menggunakan uji regresi berganda.

Hasil penelitian menunjukkan bahwa air bersih yang memenuhi syarat bakteriologis yaitu 27 sampel dan 64 tidak memenuhi syarat. Konstruksi sumur yang memenuhi syarat adalah 19 dan 72 tidak memenuhi syarat kesehatan. Sumber pencemar yang meliputi resapan septictank, air kotor, tempat pembuangan sampah, dan kandang ternak. Hasil analisa statistik diketahui bahwa lokasi, dinding sumur dan lantai memiliki pengaruh terhadap kualitas bakteriologis air bersih. Bibir sumur tidak memiliki pengaruh terhadap kualitas bakteriologis air bersih.

Kontruksi sumur meliputi lokasi, dinding sumur dan lantai mempengaruhi kualitas bakteriologis air bersih. Disarankan kepada puskesmas untuk melakukan penyuluhan mengenai konstruksi sumur yang memenuhi syarat kesehatan dan penyakit yang dapat ditularkan oleh air yang tercemar. Dan puskesmas hendaknya melakukan pemeriksaan kualitas bakteri secara rutin.
\end{abstract}

Kata Kunci : Air Bersih, konstruksi sumur gali, kualitas bakteriologis

\section{PENDAHULUAN}

Air bersih merupakan satu diantara kebutuhan pokok manusia untuk kelangsungan hidupnya. Masyarakat pada umumnya menggunakan air bersih yang bersumber dari air tanah, air hujan dan air permukaan. Sarana air bersih masyarakat biasa memanfaatkan melalui berbagai sarana misalnya dengan penampungan air hujan, sumur gali, pompa air dan lain-lain.

Berdasarkan RISKESDAS 2013, Hasil menunjukkan bahwa jenis sumber air untuk seluruh kebutuhan rumah tangga di Indonesia pada umumnya adalah sumur gali terlindung $(29,2 \%)$, sumur pompa $(24,1 \%)$, dan air ledeng/PDAM (19,7\%). Di perkotaan lebih banyak rumah tangga yang menggunakan air dari sumur bor/pompa (32,9\%) dan air ledeng/PDAM $(28,6 \%)$, sedangkan di perdesaan lebih banyak yang menggunakan sumur gali terlindung $(32,7 \%)$ (BP2K, 2013)
Berdasarkan profil Kesehatan Kabupaten Lumajang tahun 2016, sarana air bersih yang digunakan oleh masyarakat Kabupaten Lumajang yaitu sumur gali terlindung $(25,04 \%)$, sumur gali dengan pompa $(35,61 \%)$, sumur bor dengan pompa $(1,43 \%)$, terminal air $(5,03 \%)$, mata air terlindung (2,02\%), penampungan air hujan $(0,23 \%)$ dan perpipaan (30,64\%) (Dinas

Kesehatan Kabupaten Lumajang, 2016).

Persentase penduduk Kabupaten Lumajang dengan akses berkelanjutan terhadap air berkualitas (layak) yaitu sebesar 45\%. Puskesmas Tekung merupakan satu diantara Puskesmas yang ada di Kabupaten Lumajang dengan jumlah 33.447 penduduk. Jumlah penduduk dengan akses berkelanjutan terhadap air berkualitas (layak) yaitu 515 penduduk atau 2\% (Dinas Kesehatan Kabupaten Lumajang , 2016). 
Wilayah kerja Puskesmas Tekung terdiri dari 8 desa yang ada di Kecamatan Tekung. Sarana air bersih yang digunakan oleh penduduk Tekung yaitu sumur gali terlindung. Jumlah sarana air bersih sebanyak 7.320 sumur, akan tetapi yang memenuhi syarat kesehatan hanya 103 sumur atau $1,4 \%$ (Dinas Kesehatan Kabupaten Lumajang, 2016).

Persyaratan untuk penyediaan air bersih dari sumur perlu memperhatikan kualitas air sumurnya dengan memperhatikan konstruksi sumur, sumber pencemar dan cara pengolahan sebelum dikonsumsi (Sarudji, D., 2010). Persyaratan kesehatan untuk sumur gali meliputi beberapa komponen yaitu lokasi, lantai, bibir sumur dan dinding sumur (Waluyo, L., 2005).

Sumber air bersih baik air permukaan maupun air tanah harus mendapatkan perlindungan sebaik-baiknya agar mendapatkan manfaat yang optimum dan mencegah terjadinya penurunan kuantitas maupun kualitas air bersih. Air untuk keperluan Higiene Sanitasi adalah air dengan kualitas tertentu yang digunakan untuk keperluan sehari-hari yang kualitasnya berbeda dengan kulaitas air minum (PERMENKES No. 32 Tahun 2017). Kualitas air yang digunakan masyarakat harus memenuhi syarat kesehatan agar terhindar dari gangguan kesehatan. Syarat kesehatan yang meliputi persyaratan mikrobiologi, fisika, kimia dan radioaktif. Persyaratan mikrobiologi yaitu total koliform (MPN).

\section{HASIL PENELITIAN DAN PEMBAHASAN Kualitas Bakteriologis Air Bersih Sumur Gali}

Tabel 1

KUALITAS BAKTERIOLOGIS AIR BERSIH SUMUR GALI DI WILAYAH KERJA PUSKESMAS TEKUNG TAHUN 2017

\begin{tabular}{clcc}
\hline No. & \multicolumn{1}{c}{ Kualitas Bakteriologis Air } & Frekuensi & Persentase (\%) \\
\hline 1. & Memenuhi Syarat & 27 & 30 \\
\hline 2. & Tidak Memenuhi Syarat & 64 & 70 \\
\hline & Jumlah & 91 & 100 \\
\hline
\end{tabular}

Adanya bakteri E.coli dapat menyebabkan gangguan pada manusia berupa penyakit perut (diare) karena mengandung bakteri patogen (Joko, T., 2010).

Penelitian ini bertujuan menilai kualitas bakteriologis air bersih. Menilai konstruksi sumur gali yang meliputi lokasi, dinding sumur, bibir sumur dan lantai. Menganalisis pengaruh konstruksi sumur gali ditinjau dari aspek lokasi, dinding sumur, bibir sumur dan lantai.

\section{METODE PENELITIAN}

Penelitian ini merupakan penelitian survei analitik, karena pada penelitian ini melihat pengaruh antara variabel dependen dan variabel independen. Dengan menggunakan pendekatan studi cross sectional, dimana pada penelitian ini variabel dependen dan independen dilakukan pada satu saat (serentak) (Budiman, 2011). Populasi pada penelitian ini adalah sumur gali penderita diare di Wilayah Kerja Puskesmas Tekung yaitu sebanyak 995 . Jumlah sampel yaitu 91. Variabel dependen pada penelitian ini yaitu kualitas bakteriologis air bersih. Variabel independen yaitu konstruksi sumur gali ditinjau dari aspek lokasi, dinding sumur, bibir sumur dan lantai. Data yang diperoleh dari hasil observasi dan laboratorium diolah dengan menggunakan analisis secara univariat dan bivariat. Analisis bivariat pada penelitian ini menggunakan analisa regresi berganda. 
Tabel 1 menunjukkan bahwa hasil pemeriksaan laboratorium kualitas bakteriologis air bersih dari 91 sampel yang diambil di wilayah kerja Puskesmas Tekung $30 \%$ (27 sampel) memenuhi syarat dan $70 \%$ (64 sampel) tidak memenuhi syarat.

Standar baku mutu air sesuai ketentuan Permenkes RI No.32MENKES/PER/2017, total coliform yang memenuhi syarat untuk keperluan hygiene sanitasi yaitu 50 MPN/100 ml untuk dapat menjadi air bersih yang layak digunakan oleh masyarakat.

Kualitas bakteriologis yang tidak memenuhi syarat dapat disebabkan karena konstruksi sumur yang tidak memenuhi syarat kesehatan. Seperti lokasi sumur dengan sumber pencemar kurang dari 11 meter, dinding sumur kedap air kurang dari 3 meter, bibir sumur kurang dari $70 \mathrm{~cm}$, dan lantai sumur kedap air kurang dari 1 meter.

Berdasarkan penelitian (Pramudita Dewi, 2016) banyaknya kandungan bakteriologis dipengaruhi pada kondisi fisik sumur yang buruk dan kondisi sekitar seperti terdapat adanya sepictank, jamban, tempat sampah, kolam ikan, hewan ternak maupun aliran sungai yang terlalu dekat dengan sumber air.

Menurut Waluyo, Lud (2005) untuk memperbaiki kualitas dan penyediaan air itu sendiri dapat dilakukan pengolahan air. Intensitas pengolahan tergantung dari derajat pencemaran dan kontaminasi terhadap sumber air. tujuan utama pengolahan air adalah melindungi konsumen dari patogen dan hal-hal lain yang dapat mengganggu kesehatan manusia. Pengolahan air yang dapat dilakukan yaitu pra disinfeksi, koagulasi, filtrasi dan disinfeksi.

\section{Konstruksi Sumur Gali}

\section{Tabel 2}

KONSTRUKSI SUMUR GALI

DI WILAYAH KERJA PUSKESMAS TEKUNG TAHUN 2017

\begin{tabular}{clcc}
\hline No. & \multicolumn{1}{c}{ Konstruksi Sumur Gali } & Frekuensi & Persentase (\%) \\
\hline 1. & Memenuhi Syarat & 19 & 21 \\
\hline 2. & Tidak Memenuhi Syarat & 72 & 79 \\
\hline & Jumlah & 91 & 100 \\
\hline & a. Lokasi & 32 & 35 \\
& Memenuhi Syarat & 59 & 65 \\
& Tidak Memenuhi syarat & & \\
& b. Dinding sumur & 70 & 77 \\
& Memenuhi Syarat & 21 & 23 \\
& Tidak Memenuhi syarat & 58 & 64 \\
c. Bibir sumur & 33 & 36 \\
& Memenuhi Syarat & & \\
$\quad$ Tidak Memenuhi syarat & 52 & 57 \\
d. Lantai & 39 & 43 \\
& Memenuhi Syarat & & \\
& Tidak Memenuhi syarat & &
\end{tabular}

Tabel 2 menjelaskan bahwa hasil observasi di lapangan konstruksi sumur dari 91 sampel sumur gali yang diambil di wilayah kerja Puskesmas Tekung 21\% (19 sampel) memenuhi syarat dan $79 \%$ (72 sampel) tidak memenuhi syarat. Lokasi atau jarak sumur dengan sumber pencemar $35 \%$ (32 sampel) memenuhi syarat dan $65 \%$ (59 sampel) tidak memenuhi syarat. Dinding $77 \% \quad(70$ sampel) memenuhi syarat dan $23 \%$ (21 sampel) tidak memenuhi syarat. Bibir sumur $64 \%$ (58 sampel) memenuhi syarat dan 36\% (33 sampel) tidak memenuhi syarat. Lantai $57 \% \quad$ (52 sampel) memenuhi syarat dan $43 \%$ (39 sampel) tidak memenuhi syarat.

Menurut hasil observasi di lapangan yang telah dilakukan bahwa lokasi sumur di wilayah kerja Puskesmas Tekung masih 
banyak yang tidak memenuhi syarat kesehatan. Hal ini disebabkan karena jarak antara sumur dengan sumber pencemar < 11 meter. Sumber pencemar diantaranya yaitu resapan septictank, air kotor , tempat pembuangan sampah, dan kandang ternak.

Menurut Pandu Haryo. W dkk (2015), Faktor-faktor lain yang mempengaruhi keberadaan bakteri pada sumur yaitu satu diantaranya jenis tanah. Jenis tanah yang ada di wilayah kerja Puskesmas Tekung termasuk tanah alluvial atau lempung. Berdasarkan hasil penelitian Ekrar Winata dan Eddy. H (2013) menyatakan Faktor yang dapat menyebabkan persebaran E.coli yang sangat tinggi pada daerah Kelurahan Babatan-Babadan adalah jenis tanahnya yaitu alluvial dengan lapisan lempung. Pada umumnya jenis tanah alluvial memiliki tingkat porositas tinggi tetapi daya perkolasi dan permeabilitasnya rendah. Menurut Sosrodarsono dan Kensaku.T yaitu tanah lempung memiliki porositas yang sangat besar tetapi permeabilitasnya kecil karena pori-pori tanahnya sangat kecil sehingga kemampuan tanah melewatkan air menjadi berkurang. Berdasarkan hasil penelitian Irawan Wisnu dan Badrus. Z adalah kondisi wilayah penelitian dengan porositas tinggi namun permeabilitas rendah jika dikaitkan dengan teori maka pergerakan bakteri yang mengikuti aliran air tanah seharusnya kecil namun kenyataan dilapangan menunjukkan hal sebaliknya. Hal ini dapat dijelaskan bahwa bakteri dapat masuk dan mencemari air sumur melalui air sebagai media transportasinya.

Dinding sumur berdasarkan hasil observasi (sesuai tabel V.2) masih ada yang tidak memenuhi syarat kesehatan. Adapun dinding yang kedap air $<3$ meter , dan ada dinding yang $>3$ meter namun tidak kedap air. Hal ini dapat terjadi perembesan air/pencemaran bakteri dengan karakteristik habitat hidup pada kedalaman tersebut. Perembesan itu sendiri dapat berasal dari sumber pencemar yang ada di sekeliling sumur.

Bibir sumur menurut hasil observasi (sesuai tabel V.2) masih ada yang tidak memenuhi syarat. Bibir sumur yang tidak memenuhi syarat yaitu tidak kedap air dan $<70 \mathrm{~cm}$. Adapun bibir sumur yang kedap air namun tinggi $<70 \mathrm{~cm}$. Hal ini dapat terjadi pengotoran dari air permukaan karena aktifitas di sekitar sumur.

Lantai berdasarkan hasil observasi (sesuai tabel V.2) masih ada yang tidak memenuhi syarat dikarenakan lantai tidak kedap air $<1$ meter.

Berdasarkan penelitian (Nining, 2007) konstruksi sumber air bersih yang paling memberikan pengaruh signifikan terhadap kandungan bakteriologis air. Penelitian (Radjak, 2013) menyatakan pengaruh kondisi fisik sumber air bersih terhadap jumlah bakteri yaitu semakin baik kondisi fisik sumber air bersih maka kandungan bakteriologis air sumur semakin sedikit, sebaliknya jika semakin buruk kondisi fisik sumber air bersih maka kandungan bakteriologis sumber air bersih akan semakin banyak.

\section{Analisis pengaruh konstruksi sumur terhadap kualitas bakteriologis air bersih.}

Dari hasil analisa regresi berganda nilai Sig. untuk pengaruh konstruksi sumur terhadap kualitas bakteriologis air bersih sebesar $0,000<0,05$ dan nilai $F$ hitung $14.682>\mathrm{F}$ tabel 3.09. Nilai Sig. untuk pengaruh lokasi terhadap kualitas bakteriologis air bersih sebesar $0,00<$ 0,05 dan nilai $t$ hitung $5953>\mathrm{t}$ tabel 1991. Nilai Sig. untuk pengaruh dinding sumur terhadap kualitas bakteriologis air bersih sebesar 0,047<0,05 dan nilai $\mathrm{t}$ hitung $2017>\mathrm{t}$ tabel 1991. Nilai Sig. untuk pengaruh bibir sumur terhadap kualitas bakteriologis air bersih sebesar $0,295>0,05$ dan nilai t hitung $-1053<\mathrm{t}$ tabel 1991. Nilai Sig. untuk pengaruh lantai terhadap kualitas bakteriologis air bersih sebesar 0,047<0,05 dan nilai $\mathrm{t}$ hitung $2014>\mathrm{t}$ tabel 1991. Hasil analisis statistik menunjukkan bahwa lokasi terbukti berpengaruh terhadap kualitas bakteriologis pada air sumur gali.

Menurut penelitian yang dilakukan oleh Nurmala Febriyanti. R (2013), diperoleh bahwa pengaruh jarak septic tank terhadap bakteri E.coli air sumur gali di Desa Molohu tidak signifikan atau pengaruhnya sangat lemah. Hal ini dipengaruhi oleh adanya sumber 
pencemar lain selain septic tank yang jaraknya tidak terlalu jauh dengan sumur gali milik warga Desa Molohu, salah satunya adalah tempat pembuangan sampah yang berasal sari rumah tangga dan adanya tempat pemeliharaan hewan ternak atau kandang yang berada dekat dengan beberapa sumur warga yang berada di Desa Molohu.

Menurut Lud Waluyo (2005) Persyaratan kesehatan untuk sarana air bersih jarak sumur gali minimal 11 meter dari sumber pencemar antara lain : jamban, air kotor, tempat pembuangan sampah, kandang ternak dan lain-lain.

Di wilayah kerja Puskesmas Tekung sumber pencemar itu sendiri yaitu resapan septictank, air kotor, tempat pembuangan sampah dan kandang ternak. Ini sebabnya mengapa lokasi sumur dengan sumber pencemar memiliki pengaruh terhadap kualitas bakteriologis pada air sumur.

\section{Analisis Dinding Sumur terhadap Kualitas Bakteriologis Air Bersih}

Berdasarkan hasil analisis statistik menunjukkan bahwa dinding sumur terbukti berpengaruh terhadap kualitas bakteriologi pada air sumur gali.

Penelitian ini sejalan dengan penelitian yang telah dilakukan oleh Irawan, M., Rillyani dan Farich, A., (2013) tentang hubungan konstruksi sumur gali terhadap kualitas bakteriologis air pada sumur gali di Kelurahan Tejosari Kecamatan Metro Tahun 2013, terdapat hubungan yang signifikan antar dinding sumur dengan kualitas bakteriologi sumur gali. Adanya dinding sumur yang tidak memenuhi syarat memungkinkan terjadinya pencemaran kualitas air sumur gali baik secara fisik dan bekteriologi. Kualitas bakteriologi air sumur gali dapat di pengaruhi oleh sumber pencemar yang ada di sekitar sumur yang masuk membawa mikroorganisme yang meresap ke dalam sumur kembali.

Sumber air bersih yang kedalaman kedap airnya < 3 meter dapat memperbesar kemungkinan terkontaminasinya sumber air bersih sehingga akan mengakibatkan penurunan kualitas air dan pada akhirnya dapat mempengaruhi tingkat kesehatan pemakai (Hasnawi, 2012).
Menurut Entjang, I (2000) dinding sumur minimal sedalam 3 meter dari permukaan tanah dibuat dari tembok yang tak tembus air (di semen). Hal tersebut agar tidak terjadi perembesan air / pencemaran oleh bakteri dengan karakteristik habitat hidup pada kedalaman tersebut.

\section{Analisis Bibir Sumur terhadap Kualitas Bakteriologis Air Bersih}

Hasil analisis statistik menunjukkan bahwa bibir sumur terbukti tidak berpengaruh terhadap kualitas bakteriologi pada air sumur gali.

Menurut Entjang, I., 2000 tinggi bibir sumur minimal $70 \mathrm{~cm}$ dari lantai, terbuat dari bahan yang kuat dan rapat air untuk mencegah pengotoran dari air permukaan dan untuk keselamatan

Berdasarkan penelitian Irawan, M., Rillyani dan Farich, A., (2013) tentang hubungan konstruksi sumur gali terhadap kualitas bakteriologis air pada sumur gali di Kelurahan Tejosari Kecamatan Metro Tahun 2013, terdapat hubungan yang signifikan antar bibir sumur dengan kualitas bakteriologis air sumur gali. Adanya bibir sumur dan jarak sumber pencemar sumur yang tidak memenuhi syarat memungkinkan terjadinya pencemaran kualitas air sumur gali baik secara fisik dan bakteriologi. Kualitas bakteriologi air sumur gali dapat dipengaruhi oleh pengotor yang berasal dari permukaan tanah yang ada di sekitar sumur yang masuk membawa mikroorganisme ke dalam sumur kembali. Hasil observasi menunjukkan bahwa bibir sumur $64 \%$ sudah memenuhi syarat kesehatan. Tidak adanya pengaruh bibir sumur dapat diakibatkan oleh variabel yang tidak diteliti yaitu jenis tanah. Menurut Pandu Haryo. W dkk (2015), Faktor-faktor lain yang mempengaruhi keberadaan bakteri pada sumur yaitu satu diantaranya jenis tanah.

\section{Analisis Lantai terhadap Kualitas Bakteriologis Air Bersih}

Menurut hasil analisis statistik menunjukkan bahwa lantai terbukti berpengaruh terhadap kualitas bakteriologi pada air sumur gali. 
Pada hasil penelitian Prajawati (2008), hasil analisis statistiknya menunjukkan bahwa terdapat hubungan yang signifikan lantai sumur dengan kualitas mikrobiologis air sumur .

Berdasarkan penelitian Irawan, M., Rillyani dan Farich, A., (2013) tentang hubungan konstruksi sumur gali terhadap kualitas bakteriologis air pada sumur gali di Kelurahan Tejosari Kecamatan Metro Tahun 2013,

Tidak ada hubungan antara lantai sumur gali dengan kualitas bakteriologis air sumur gali. Adanya lantai sumur yang tidak memenuhi syarat memungkinkan terjadinya pencemaran kualitas air sumur gali baik secara fisik dan bakteriologi. Kualitas bakteriologi air sumur gali dapat dipengaruhi oleh air resapan kedalam tanah yang membawa mikroorganisme dalam air yang meresap ke dalam sumur kembali.

Menurut Lud Waluyo (2005) Lantai harus kedap air minimal 1 meter dari sumur, tidak retak / bocor, mudah dibersihkan, dan tidak tergenang air.

\section{Kesimpulan}

1. Kualitas bakteriologis air bersih sumur gali di wilayah kerja Puskesmas Tekung Tahun 2017 30\% memenuhi syarat dan $70 \%$ tidak memenuhi syarat.

2. Konstruksi sumur gali di wilayah kerja Puskesmas Tekung Tahun 2017 21\% memenuhi syarat dan $79 \%$ tidak memenuhi syarat. Konstruksi sumur gali yang meliputi :

a. Lokasi sumur gali $35 \%$ memenuhi syarat dan $65 \%$ tidak memenuhi syarat.

b. Dinding sumur gali $77 \%$ memenuhi syarat dan $23 \%$ tidak memenuhi syarat.

c. Bibir sumur gali $64 \%$ memenuhi syarat dan $36 \%$ tidak memenuhi syarat.

d. Lantai sumur gali $57 \%$ memenuhi syarat dan $43 \%$ tidak memenuhi syarat.

3. Ada pengaruh konstruksi sumur gali yang meliputi lokasi, dinding sumur, dan lantai terhadap kualitas bakteriologis air bersih di wilayah kerja Puskesmas Tekung Tahun 2017.
4. Tidak ada pengaruh bibir sumur terhadap kualitas bakteriologis air bersih di wilayah kerja Puskesmas Tekung Tahun 2017.

\section{Saran}

Disarankan kepada puskesmas untuk melakukan penyuluhan mengenai konstruksi sumur yang memenuhi syarat kesehatan dan penyakit yang dapat ditularkan oleh air yang tercemar. Dan puskesmas hendaknya melakukan pemeriksaan kualitas bakteri secara rutin.

\section{DAFTAR PUSTAKA}

Dinas Kesehatan Kabupaten Lumajang. 2016. Profil Dinas Kesehatan Kabupaten Lumajang 2016. Lumajang

Haryo Wibowo, P, dkk. 2014. Kajian Kualitas Air Sumur Resapan Kota Surakarta di Tinjau dari Parameter Escherichia Coli. Jurnal EKOSAINS. Vol.7 No.2.15 Juli 2015.

http://www.distrodoc.com/632542kajian-kualitas-sumur-resapan-kotasurakarta-ditinjau-dari

Hasnawi, Heriyani. 2012. Pengaruh Konstruksi Sumur terhadap Kandungan Bakteri Escherichia Coli Pada Air Sumur Gali di Desa Dopalak Kecamatan Paleleh Kabupaten Buol. Universitas Gorontalo.

https://media.neliti.com/media/publi cations/37244-ID-pengaruh-

konstruksi-sumur-terhadap-

kandungan-bakteri-eschercia-colipada-air-sum.pdf

Irawan, Masa., Rillyani, \& Farich, Achmad, 2013. Hubungan Konstruksi Sumur Gali Terhadap Kualitas Bakteriologis Air pada Sumur Gali di Kelurahan Tejosari Kecamatan Metro Timur Tahun 2013. Jurnal Kesehatan Holistik. Vol.8 No.1. Januari 2014. 21-25 Januari 2014.

Joko, Tri, 2010. Unit Air Baku dalam Sistem Penyediaan Air Minum. Semarang, Graha Ilmu. $1^{\text {st }}$ Edition : $8,13$.

Nining. 2007. Pengaruh Kondisi Lingkungan terhadap Kandungan Bakteriologis Air Sumur Gali di Desa manjung, Kecamatan Ngawen, Kabupaten Klaten, Jawa Tengah. 
Notoatmodjo, Soekidjo, 2012. Metodologi Penelitian Kesehatan. Jakarta. PT.Rineka Cipta. $1^{\text {st }}$ Edition : 104, 182

Peraturan Menteri Kesehatan Republik Indonesia Nomor 32Tahun 2017 Tentang Standar Baku Mutu Kesehatan Lingkungan Dan Persyaratan Kesehatan Air Untuk Keperluan Higiene Sanitasi, Kolam Renang, Solus Per Aqua, Dan Pemandian Umum.

Prajawati, R. 2008. Hubungan Konstruksi dengan Kualitas Mikrobiologi Air Sumur Gali

Radjak, Nurmala Febriyanti, 2013. Pengaruh Jarak Septic Tank dan Kondisi Fisik Sumur Terhadap Keberadaan Bakteri Escherichia Coli pada Sumur Gali. Gorontalo. Universitas Negeri Gorontalo. https://www.scribd.com/document/3 35733894/2767-2757-1-PB
Waluyo, Lud, 2005. Mikrobiologi Lingkungan. Malang. Universitas Muhammadiyah Malang. $1^{\text {st }}$ Edition : 118-122, 153-162, 256-257.

Wardhana, W \& Zaman, B. 2004. Pengaruh Porositas dan Permeabilitas Tanah serta Jarak Tangki Septik terhadap Konsentrasi Bakteri Escherichia Coli dalam Air Tanah Dangkal di Wilayah Pesisir. Jurnal Presipitasi. Vol.4 No.1 Maret 2008.

Winata, E. 2013. Kualitas Air Tanah di Sepanjang Kali Gajah Wong Ditinjau dari Pola Sebaran Escherichia Coli. Jurnal Fisika Indonesia. Vol.XVII No.50. Agustus 2013. 